\title{
A proteomic analysis of acute leukemia cells treated with 9-hydroxyoctadecadienoic acid
}

\author{
Zhen Li, Bohong Chen, Ping Wang, Xin Li, Gaotai Cai, Wei Wei and Wenqi Dong*
}

\begin{abstract}
Background: 9s-hydroxy-octadecadienoic acid (9S-HOD), one of the natural products of linoleic acid oxygenation by 15-lipoxygenase (15-LOX), has been found to have anti-tumor properties in vitro and in vivo. The present study therefore investigated whether 9S-HOD affects acute leukemia HL-60 cells.

Methods: The cytotoxicity of 9S-HOD in HL-60 with or without the presence of fetal bovine serum (FBS) in the culture media was tested using cell viability assays and flow cytometry. To explore the mechanism of its anti-tumor activity by $95-H O D$, we used a proteomic analysis to identify HL-60 cells protein profiles, based on two-dimensional gel electrophoresis (2-DE) and mass spectrometry (MS) identification.

Results: 9S-HOD exerted cytotoxicity efficacy and induced apoptosis in HL-60 cells, and the cytotoxicity was largely attenuated by the presence of FBS in culture media. The proteomic results revealed that 9S-HOD remarkably altered the abundance of 23 proteins that were involved in mRNA metabolic process, protein binding, DNA replication and apoptosis.
\end{abstract}

Conclusions: Our results indicated that 9S-HOD exerts cytotoxicity in HL-60 cells by affecting several pathways.

Keywords: 9s-hydroxy-octadecadienoic acid, Acute leukemia cells, Proteomics, Bioinformatics analysis

\section{Background}

Leukemia is one of the most common cancers in the world, especially the type of acute myeloid leukemia (AML). AML is characterized by the uncontrolled growth of abnormal white blood cells in the bone marrow and interfere with the production of normal blood cells [1]. Most current treatment strategies kill cancerous cells by chemotherapeutic agents with a number of severe toxic side-effects [2]. Therefore, the search for new anti-leukemia treatments has increased and natural products or their derivatives have been an important source due to their diverse activities [3].

Naturally occurring oxylipins, known as oxidized metabolites of long chain polyunsaturated fatty acids, have important roles in animals and plants for cell signaling and defense in response to attack from microbes or pathogens [4]. The hydroxyl-octadecadienoic acids (HODEs) are the major reaction products of linoleic acid oxygenation by 15LOXenzyme, including 9-hydroxy-octadecadienoic acid

\footnotetext{
* Correspondence: dongwq63@263.net

School of Laboratory Medicine and Biotechnology, Southern Medical

University, Guangzhou, Guangdong Province 510515, People's Republic of China
}

(c) The Author(s). 2016 Open Access This article is distributed under the terms of the Creative Commons Attribution 4.0 International License (http://creativecommons.org/licenses/by/4.0/), which permits unrestricted use, distribution, and reproduction in any medium, provided you give appropriate credit to the original author(s) and the source, provide a link to the Creative Commons license, and indicate if changes were made. The Creative Commons Public Domain Dedication waiver (http://creativecommons.org/publicdomain/zero/1.0/) applies to the data made available in this article, unless otherwise stated. HOD) [5]. HODEs are well-known for its antiinflammatory properties, particularly in cardiovascular and other inflammatory diseases [6]. Recently, studies have demonstrated that HODEs are associated with a number of cancers, revealing possible novel drugs for chemoprevention and/or treatment of a number of cancers prevention [7-9].

Multiple cellular and molecular mechanisms seem to be involved in the anti-cancer effects of HODEs. Hampel et al. [10] indicated that 9- and 13-HODE, as endogenous fatty acid ligands for PPAR $\gamma$, possess differential, ligand specific actions in monocytic cells to regulate cell cycle progression, apoptosis and PPAR $\gamma 2$ gene expression. Interesting, recent studies show that (S)-HODE decrease cell growth and DNA synthesis, and induce apoptosis of Caco-2 cells, whereas (R)-HODE presents the opposite action [11]. Therefore, the present study considered whether 9S-HOD affects acute leukemia HL60 cells, and what is the mechanism? The aim of this study was to investigate the effects of 9S-HOD on acute leukemia HL-60 cells. Furthermore, 9S-HOD-treated 
HL-60 cells were analyzed by a 2D-gel based proteomics approach and differentially expressed proteins were identified by mass spectrometry. The integration of proteomics and bioinformatics analyses revealed 9S-HOD may affect several pathways.

\section{Methods}

Materials

HODs ( $\geq 98.0 \%$, HPLC) were purchased by Larodan Fine Chemicals AB (Solna, Sweden), t10,c12-Conjugated linoleic acid (t10,c12-CLA, $\geq 96.0 \%$, HPLC) were purchased from Aldrich Chemical Co (Milwaukee, USA). RPMI 1640, CD Hybridoma, AIM-V media, Apoptosis Assay Kit\#2 and Trizol LS were purchased from GIBCO (Carlsbad, USA). All reagents for 2-D electrophoresis were obtained from Amersham Pharmacia Biotech (Uppsala, Sweden).

\section{Cell culture and cell viability assay}

HL-60 cells were obtained from the Chinese Academy of Sciences Cell Bank. They were cultured in RPMI 1640 medium plus $10 \%$ (v/v) FBS under standard culture conditions. Prior to seeding cells to the microplates, cells media were replaced with serum (FBS)-free/ (or serum) culture media. Cells were then sub-cultured and treated with drugs which were dissolved in ethanol at a range of concentration $(7.5 \sim 240 \mu \mathrm{M})$. After $24-48 \mathrm{~h}$ incubation, CCK-8 $(20 \mu \mathrm{L})$ was added of to each well and incubated for $3 \mathrm{~h}$. The final concentration of ethanol was $<0.2 \%$ $(\mathrm{v} / \mathrm{v})$. Cell viability was measured using a microplate reader (Polarstar, BMG Labtechnologies) at a wavelength of $490 \mathrm{~nm}$. The effects of the drugs were expressed as percentage of cell viability against concentrations of drugs. Each performed in triplicate for three times.

\section{Apoptosis assay and DAPI staining}

For DAPI (4',6-Diamidino-2-Phenylindole, Dihydrochloride) staining, HL-60 cells were incubated with 9S-HOD for $48 \mathrm{~h}$. The cells were collected and incubated in $0.1 \mathrm{~mol} / \mathrm{L}$ PBS $(\mathrm{pH}=7.4)$ containing $50 \mu \mathrm{g} / \mathrm{ml}$ DAPI and $100 \mu \mathrm{g} / \mathrm{ml}$ DNase-free RNase A at $37{ }^{\circ} \mathrm{C}$ for $20 \mathrm{~min}$. Apoptotic cells were identified as typical morphology of shrinkage of the cytoplasm, membrane blebbing, and nuclear condensation and/or fragmentation. For flow cytometry analysis, cells treated with vehicle and 9S-HOD for 0-48 h were collected and stained with Annexin V-FITC and propidium iodide (PI) according to the manufacturer's protocol and analyzed by flow cytometry, followed by data analysis using Cell Quest v.3.1 Software (Becton Dickinson, USA).

\section{Protein separation by $2-\mathrm{DE}$}

HL-60 cells were cultured in RPMI 1640 media with or without 9S-HOD $(20 \mu \mathrm{M})$ for $48 \mathrm{~h}$. To perform 2-DE, the cells were dissolved in lysis buffer (7 M urea, $4 \%$
CHAPS, 40 mM Tris, 65 mM DTT). Samples were sonicated on ice for $10 \mathrm{~s}$ with an ultrasonic processor and centrifuged for $1 \mathrm{~h}$ at $40,000 \times \mathrm{g}$ at $4{ }^{\circ} \mathrm{C}$. Protein concentration was measured by the method of Bradford with bovine serum albumin used as the standard. Proteins $(120 \mu \mathrm{g})$ were resuspended with $300 \mu \mathrm{l}$ of IEF rehydration buffer (7 M urea, $2 \mathrm{M}$ thiourea, $2 \%$ CHAPS, $2 \mathrm{mM}$ TBP, $0.3 \%$ carrier ampholytes $\mathrm{pH} 3-10$, and $0.002 \%$ bromophenol blue). After sample loading, IEF gels were run at $250 \mathrm{~V}$ for $1 \mathrm{~h}, 500 \mathrm{~V}$ for $1 \mathrm{~h}, 1000 \mathrm{~V}$ for $1 \mathrm{~h}$, $10,000 \mathrm{~V}$ for $3 \mathrm{~h}, 10,000 \mathrm{~V}$ for $65,000 \mathrm{~V} . \mathrm{h}$. After IEF, IPG strips were processed to reduction and alkylation in two equilibration steps. Strips were first equilibrated for $15 \mathrm{~min}$ in $6 \mathrm{ml}$ of equilibration buffer I (1.5 M Tris $\mathrm{pH}$ 8.8, $6 \mathrm{M}$ urea, $20 \%$ glycerol, $1 \%$ SDS, and $2 \%$ DTT) and then equilibrated for $15 \mathrm{~min}$ in equilibration buffer II (1.5 M Tris pH 8.8, $6 \mathrm{M}$ urea, 20 \% glycerol, $1 \%$ SDS, and $2.5 \%$ iodoacetamide). The second dimension separation was performed with $12.5 \%$ SDS-PAGE in Protean II xicell (Bio-Rad) and run at $10 \mathrm{~mA}$ for $1 \mathrm{~h}$ and then $28 \mathrm{~mA}$ for $9.5 \mathrm{~h}$ at $16^{\circ} \mathrm{C}$, until the dye front reached the gel border. The analytical gels were visualized with silver staining method that was mass spectrometry compatible [12]. After that, the digitalized gel images were analyzed (spot detection, count and map matching) were performed using PDquest 8.0.1 software (Bio-Rad).

\section{In-Gel digestion and identification}

In-gel digestion was performed according to the method described by Rosenfeld [12]. The stained protein spots were excised from the gel and digested. The gel pieces were rinsed three times and spots were extracted with $25 \mathrm{mM} \mathrm{NH}_{4} \mathrm{HCO}_{3}$ and $50 \%$ acetonitrile, and then dried completely. The dried gels were rehydrated in a digestion buffer of $25 \mathrm{mM} \mathrm{NH} \mathrm{mCO}_{3}$ containing $10 \mathrm{ng} / \mu \mathrm{l}$ modified trypsin. The gel slices were completely covered by the digestion buffer and left to incubate overnight at $37^{\circ} \mathrm{C}$.

\section{MS identification and database search}

Peptide mixtures of each gel spot were dissolved in $0.1 \%$ TFA, desalted, and concentrated. The sample was mixed with the same volume of matrix (CHCA in $30 \%$ ACN/0.1 \% TFA), spotted on a target disk, and allowed to air-dry. The peptides were analyzed using a Bruker ultrafleXtreme MALDI-TOF mass spectrometer (Bruker Daltonics, Germany). The peptide sequence was determined with MASCOT software. The search was based on the NCBI protein database on the assumption that peptides aremonoisotopic, oxidized at methionine residues, and carbamidomethylated at cysteine residues. Mass tolerance was allowed within 150 parts/million (ppm). Proteins matching more than five peptides and with a MASCOT score higher than 60 were considered significant $(P<0.05)$. 


\section{Statistical analysis}

Each assay was repeated for three times. Values were expressed as mean \pm SD. Student's t-test were used for evaluate the statistical significant differences in groups. One-way ANOVA was used to assess the differences between the vol \% values (fold changes of spot volume) of each identified protein. GraphPad Prism 5 was used and $P$ value of $<0.05$ was considered statistically significant differences.

\section{Results}

The effect of FBS content in culture medium on cytotoxicity of 9S-HOD

The cytotoxicity of 9S-HOD in HL-60 cell was assayed by CCK-8 (Fig. 1). HL-60 cell were cultured with RPMI supplemented with $5 \%$ FBS (+FBS), RPMI without FBS (-FBS), serum-free medium CD or AIM-V for 24-72 h. The cell viability at $24 \mathrm{~h}$ was markedly inhibited by $9 \mathrm{~S}$ HOD when cultured with CD, while 9S-HOD did not show this effect in other media (Fig. 1a). The cytotoxicity of 9S-HOD cultured in + FBS or CD media for $48 \mathrm{~h}$ were significantly higher than that for $24 \mathrm{~h}$ culture (Fig. 1b). Compared the cell viability rate in + FBS with CD media for 24 and $48 \mathrm{~h}$, the cytotoxicity effect of 9SHOD was largely attenuated by the presence of FBS in culture medium. The cell viability rate by of 9S-HOD was $49.9 \%$ for $72 \mathrm{~h}$ when cultured with $5 \%$ FBS (data not shown). However, 9S-HOD did not show cytotoxicity in -FBS or AIM-V media.

HL-60 cells were cultured in + FBS, -FBS or CD media to test cell growth (Fig. 1c). With + FBS in culture medium, the cell viability rate was used as control (100\%). There was no significant difference in the cell viability rate between +FBS and CD for 24 and $48 \mathrm{~h}$ $(P>0.05$, but sharply decreased to $27.2 \%$ for $72 \mathrm{~h}$ in CD culture medium $(P<0.05)$. Meanwhile, there was significant difference in the cell viability rate between + FBS and -FBS $(P<0.05)$. In FBS-free culture medium, the cell viability rates were $49.7,30.9$ and $22.4 \%$ for 24,48 and $72 \mathrm{~h}$, respectively.

When cultured in CD medium for $48 \mathrm{~h}$ in the presence of 9S-HOD or $10 \mathrm{t}, 12 \mathrm{c}$-CLA shown concentrationdependant cytotoxicity by the reduction of CCK-8 (Fig. 1d). 10 t,12c-CLA started to show noticeable activity at $240 \mu \mathrm{M}$ while 9S-HOD shown significant cytotoxicity effect from 7.5 to $60 \mu \mathrm{M}(P<0.05)$.

To determine whether the cytotoxicity effect was caused by cell apoptosis, HL-60 cells were treated with $20 \mu \mathrm{M}$ of $9 \mathrm{~S}-\mathrm{HOD}$ for $48 \mathrm{~h}$ and DAPI staining was performed. Treated cells showed marked nuclear fragmentation and chromatin condensation which were clear indications of apoptosis (Fig. 2b), while control cells showed intact cell bodies with clear round nuclei (Fig. 2a). Meanwhile, we found a time-dependent increase
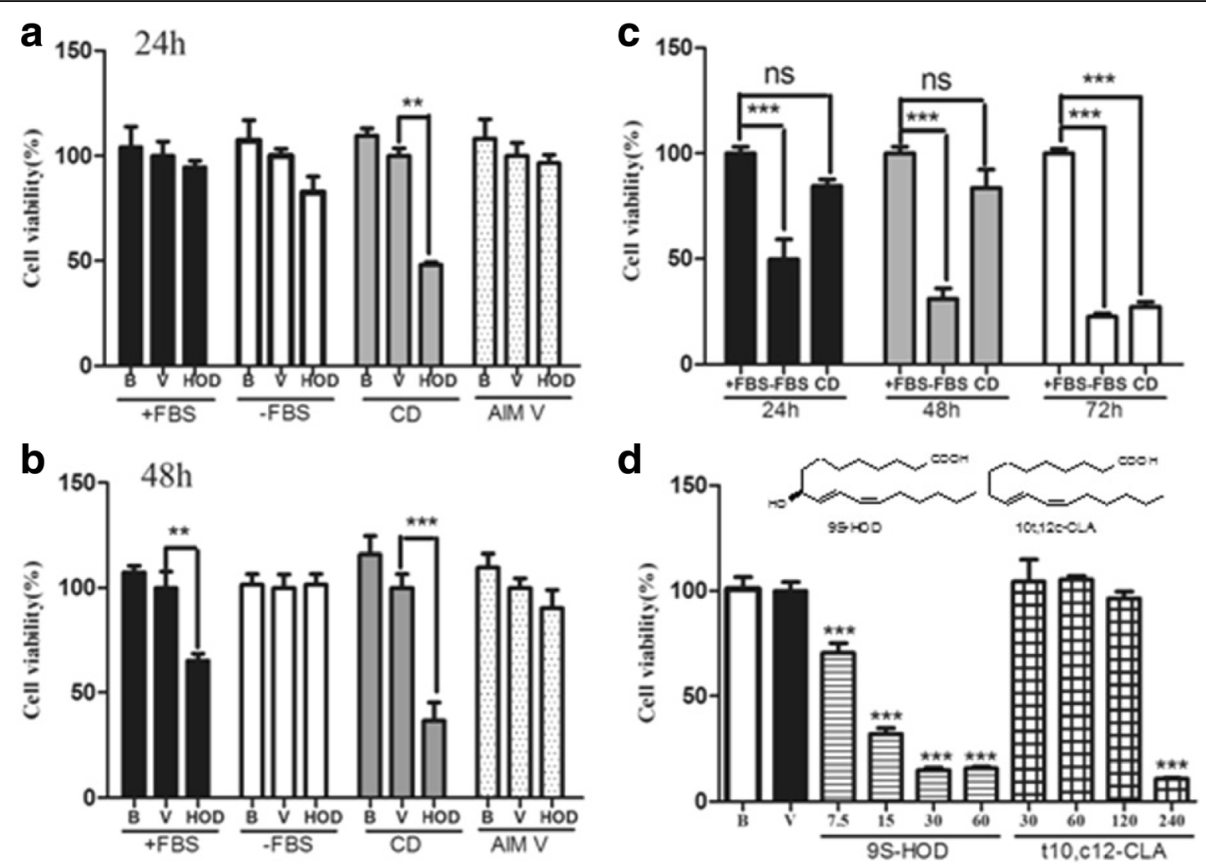

Fig. 1 The cell viability of HL-60 cell treated with/without 9S-HOD in different culture media. a Effects of 9S-HOD for $24 \mathrm{~h}$ in $+F B S,-F B S, C D$ and AIM-V media. b Effects of 9S-HOD for $48 \mathrm{~h}$ in + FBS, -FBS, CD and AIM-V media. c The cell viability of HL-60 cell for $24 \sim 72 \mathrm{~h}$ in + FBS, $-\mathrm{FBS}$ and CD media. d Effects of 9S-HOD or 10 t,12c-CLA for $48 \mathrm{~h}$ in CD medium. B: blank; V: vehicle; HOD: 9S-HOD; +FBS: RPMI medium containing $5 \%$ FBS; -FBS: RPMI medium without FBS (serum free); CD: CD hybridoma medium (serum free); AIM-V: AIM-V medium (serum free). ${ }^{*} P<0.01,{ }^{* * *} P<0.001$ 
in cell apoptosis (FITC-Annexin-V and PI double-positive cells) for $0-24 \mathrm{~h}$ after treated with 9S-HOD $(P<0.05)$, then the percentage of apoptosis cell was decreased from 24 to $48 \mathrm{~h}$ due to the late apoptosis cell increasing (Fig. 2c). Our data suggest that the cytotoxicity effect of 9S-HOD may be associated with an increase in cell apoptosis.

\section{Proteomic results and statistical analysis}

To investigate the mechanism, the protein expression changes upon 9S-HOD treatment in HL-60 cells were analyzed by 2 -DE-based proteomics approach. After $20 \mu \mathrm{M}$ 9S-HOD or vehicle treatment for $24 \mathrm{~h}$, protein lysates were prepared and separated first by IEF followed by SDS-PAGE separation; and the resulting 2-DE gel were stained with collocidal coomassie blue silver. Then the stained 2D-gel were scanned and analyzed by GE software, 3-fold differentially expressed proteins were excised and processed for further MS analysis. In Fig. 3, representative 2-DE gels of untreated (a) and 9S-HOD treated HL-60 cell (b) are shown. As a result, the 2-DE gel showed an obvious separation of cell proteins, which 1200 protein spots were detected in each gel. Comparing the spots of untreated and 9S-HOD treated HL-60 cell by PDquest software for image analysis, a total of 32 protein spots exhibited 3 -fold significant difference $(P<0.05)$. Among the 32 proteins, 20 peptide mass fingerprints (PMFs) were matched identified by
MALDI-TOF-MS and protein database searching, as displayed in Table 1.

\section{Bioinformatic analysis}

We analyzed the GO enrichment of fourteen up-regulated and six down-regulated proteins in 9S-HOD treated HL60 cells (Table 1 ) by using the http://genecodis.cnb.csic.es/ website. These dysregulated proteins were categorized into different biology processes including response to mRNA metabolic process, protein binding, DNA replication and apoptosis (Fig. 4a). STRING software was used to map a network of interacting proteins whose levels changed following 9S-HOD treatment.

\section{Discussion}

It is reported that HODs showed more potent antitumor activities than lead compound CLA, especially (S)-HOD had more activity compared with the corresponding (R)-HOD [11, 13]. To date, the mechanism of 9-HOD involved of inhibiting cell proliferation and inducing apoptosis. In this study, we also observed cytotoxicity and apoptosis in HL-60 cells after treatment of 9S-HOD, observing typical morphological changes such as chromatin condensation and fragmentation. Furthermore, the 9SHOD anti-tumor activity on HL-60 cell was severely delayed and attenuated by the presence of FBS in culture medium, which was correspond well to our previous finding on other cancer cells [14]. This may be due to serum
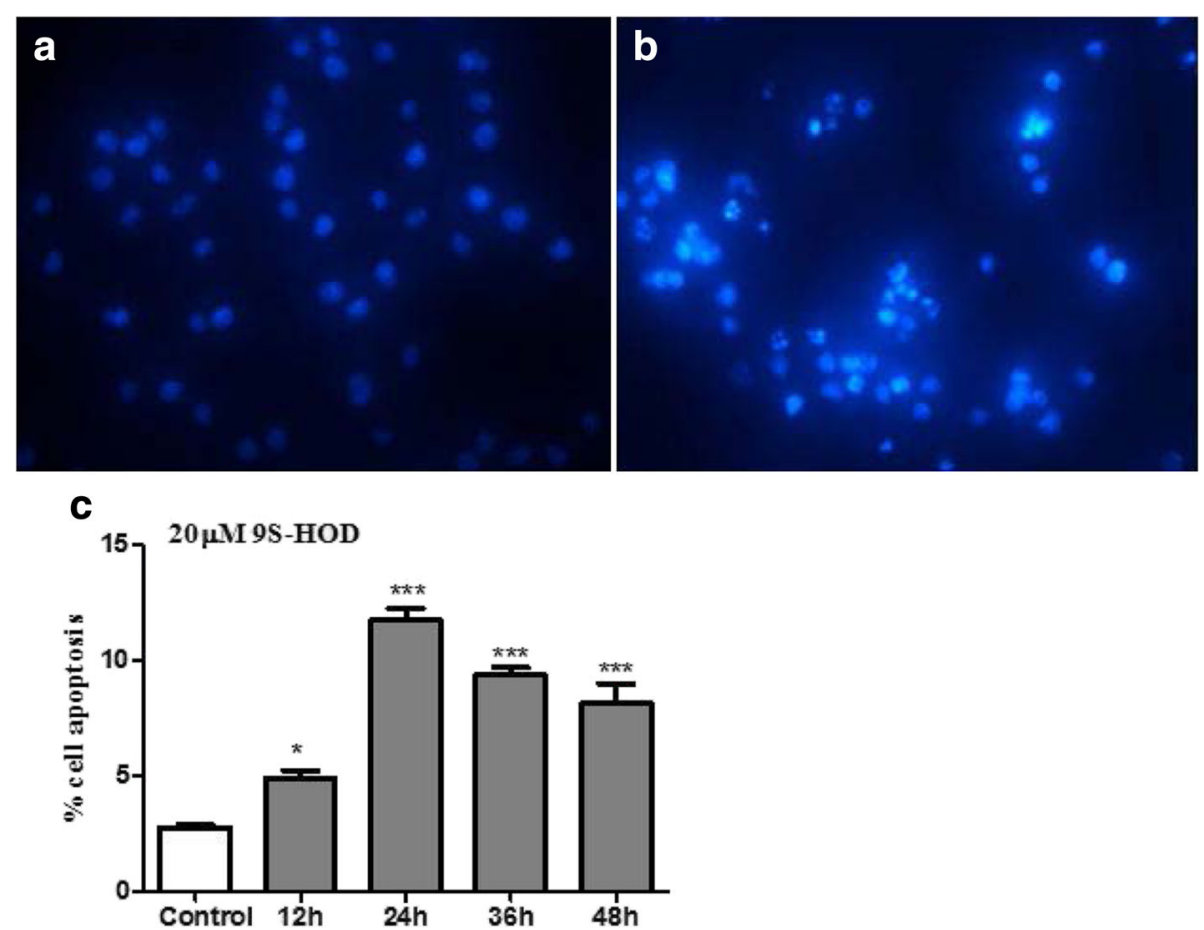

Fig. 2 9S-HOD induces HL-60 cell apoptosis. Morphological analysis of HL-60 cell after a vehicle or b $20 \mu \mathrm{M} 9 \mathrm{~S}-\mathrm{HOD}$ treatment for $48 \mathrm{~h}$, and c apoptosis examined using Annexin V/PI staining and flow cytometry. ${ }^{*} P<0.05,{ }^{* * *} P<0.001$ 


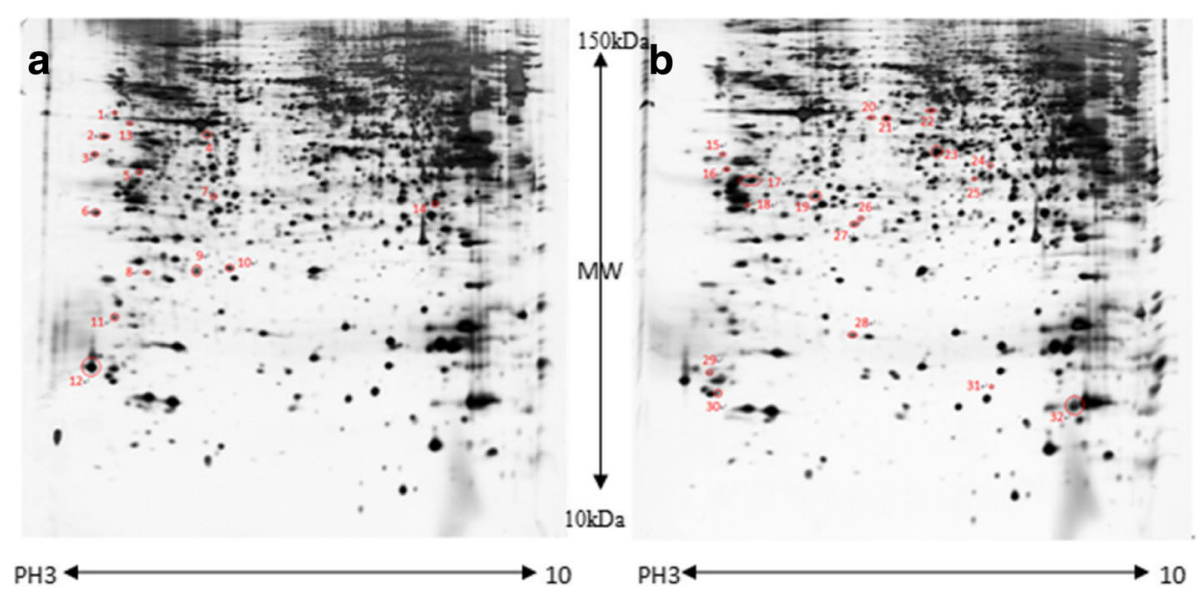

Fig. 3 Two-DE profiles of a vehicle or $\mathbf{b} 20 \mu \mathrm{M}$ 9S-HOD treatment of HL-60 for $48 \mathrm{~h}$. Total protein exacts were separated on pH 3-10, 17 cm IPG strips and stained with silver. MS-based identification of these spots is summarized in Table 1

Table 1 The identification of protein spots on 2-DE

\begin{tabular}{|c|c|c|c|c|c|c|}
\hline Spot & Accession & Protein name & Gene & M.W. & $\mathrm{pl}$ & Score \\
\hline \multicolumn{7}{|c|}{ mRNA metabolic process } \\
\hline 13 & Q69YN4 & Protein virilizer homolog $\downarrow$ & KIAA1429 & 202584.08 & 4.44 & 66.6 \\
\hline 9 & Q13185 & Chromobox protein homolog $3 \downarrow$ & CBX3 & 20969.41 & 4.96 & 84.6 \\
\hline 22 & P61978 & Heterogeneous nuclear ribonucleoprotein $\mathrm{K} \uparrow$ & HNRNPK & 48760.25 & 5.17 & 54.5 \\
\hline \multicolumn{7}{|c|}{ Protein binding } \\
\hline 32 & P60709 & Actin, cytoplasmic $1 \uparrow$ & ACTB & 42051.86 & 5.15 & 122 \\
\hline 23 & P05388 & 605 acidic ribosomal protein P0个 & RPLPO & 34388.88 & 5.77 & 170 \\
\hline 29 & P11171 & Protein $4.1 \uparrow$ & EPB41 & 81755.32 & 5.54 & 61 \\
\hline 6 & Q6PK50 & HSP90AB1 protein $\downarrow$ & HSP90AB1 & 40270.42 & 4.61 & 78.6 \\
\hline \multicolumn{7}{|c|}{ DNA replication } \\
\hline 1 & Q01105 & Protein SET $\downarrow$ & SET & 30974.22 & 3.86 & 98 \\
\hline 2 & Q01105 & Protein SET $\downarrow$ & SET & 31310.48 & 3.83 & 202 \\
\hline 5 & P12004 & Proliferating cell nuclear antigen $\downarrow$ & PCNA & 29092.42 & 4.31 & 94.1 \\
\hline \multicolumn{7}{|c|}{ Cytoskeleton } \\
\hline 21 & P63261 & Actin, cytoplasmic $2 \uparrow$ & ACTG1 & 42107.92 & 5.16 & 321 \\
\hline 17 & I3L1U9 & Actin, cytoplasmic $2, \mathrm{~N}$-terminally processed $\uparrow$ & ACTG1 & 23886.98 & 5.11 & 129 \\
\hline \multicolumn{7}{|c|}{ Apoptosis process } \\
\hline 26 & P51878 & Caspase- $5 \uparrow$ & CASP5 & 33966.33 & 8.55 & 60.4 \\
\hline \multicolumn{7}{|c|}{ Negative regulation of myeloid cell differentiation } \\
\hline 4 & E9PKG1 & Protein arginine $\mathrm{N}$-methyltransferase $1 \downarrow$ & PRMT1 & 38198.03 & 6.06 & 106 \\
\hline \multicolumn{7}{|c|}{ Unknown } \\
\hline 8 & P35527 & 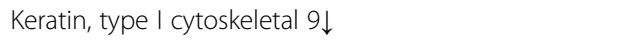 & KRT9 & 62254.9 & 4.89 & 67.1 \\
\hline 31 & Q15195 & Plasminogen-like protein $\mathrm{A} \uparrow$ & PLGLA & 11135.6 & 6.5 & 63.6 \\
\hline 28 & Q8IUZ0 & Isoform 3 of Leucine-rich repeat-containing protein $\uparrow$ & LRRC49 & 74491.59 & 7.15 & 60 \\
\hline 27 & B4DVQ0 & cDNA FLJ58286, highly similar to Actin, cytoplasmic $2 \uparrow$ & & 37666.76 & 5.45 & 147 \\
\hline 20 & B4E335 & cDNA FLJ52842, highly similar to Actin, cytoplasmic $1 \uparrow$ & & 39542.66 & 5.28 & 207 \\
\hline 19 & B4DW52 & cDNA FLJ55253, highly similar to Actin, cytoplasmic $1 \uparrow$ & & 38950.3 & 5 & 148 \\
\hline
\end{tabular}



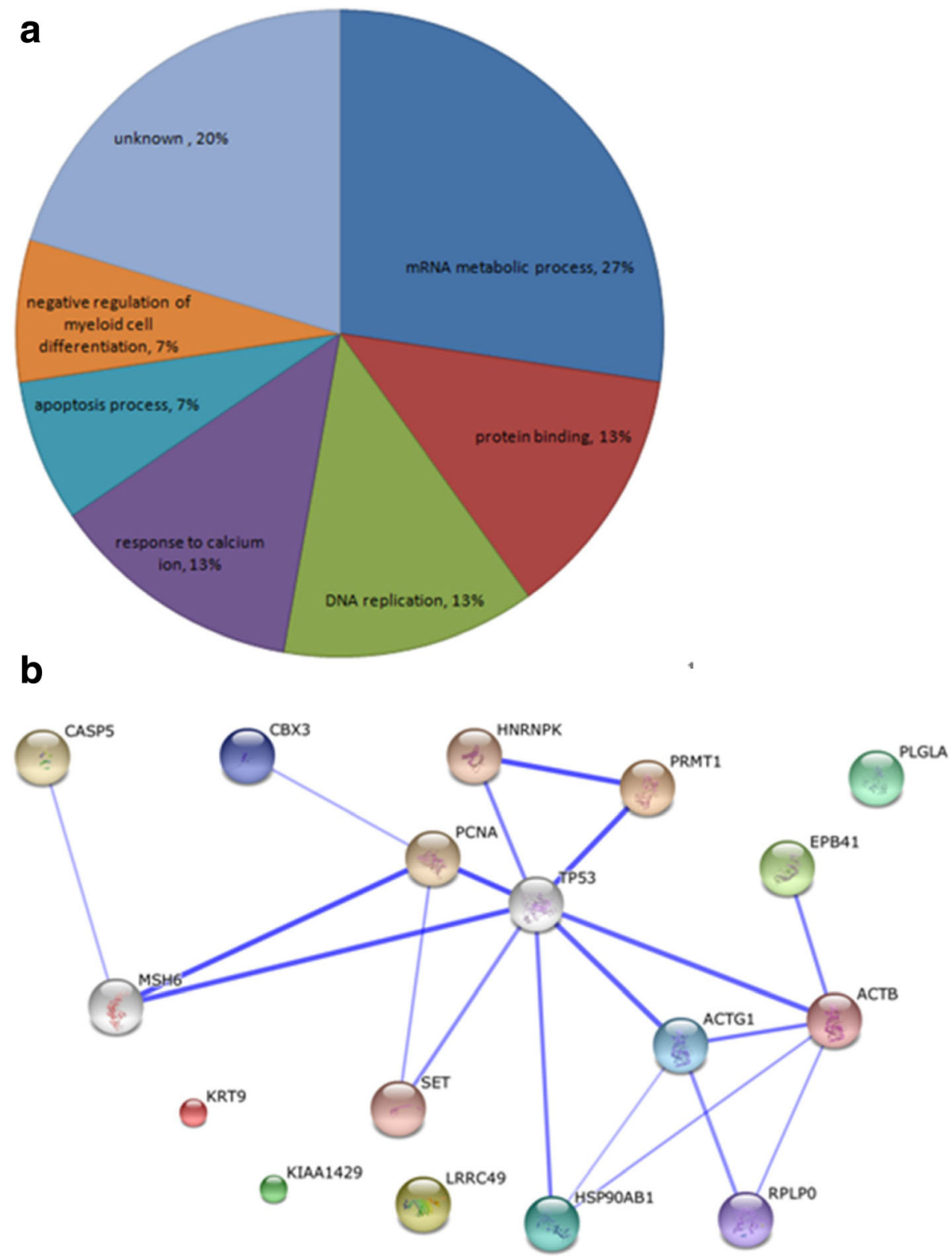

Fig. 4 Distribution of GO annotations of biological functions for identified proteins. a Multi-level pie chart of combined graph of GO biological functions annotations by Genecodis2; $\mathbf{b}$ The network of proteins was generated by STRING

albumin in culture medium could strongly bind to fatty acid [11]. Interestingly, in the present study, CD media (serum-free) were demonstration to increase the antitumor activity of 9S-HOD, whereas the activity were weak in -FBS and AIM V media (also serum-free). This may be due to the HL-60 cells grew not well in -FBS media with the cell viability of $49.7 \%$ for $24 \mathrm{~h}, 30.9 \%$ for $48 \mathrm{~h}$ compared to that in FBS media as $100 \%$.

Our proteomic study revealed differences between control and 9S-HOD treated group. 33 differentially expression proteins were found, 19 of which were successfully identified by mass spectrometry followed by NCBI database. Functional annotation analysis showed that the differential proteins were involved in various biological processes such as mRNA metabolic process, protein binding, DNA replication, response to calcium ion, apoptosis and negative regulation of myeloid cell differentiation.

In order to better understand the mechanisms of 9SHOD in HL-60, the interaction network of proteins was built by the STRING as described previously shown as Fig. $4 \mathrm{~b}$. Most of the proteins in the map have direct or indirect links, in which protein ACTB, EPB41, HSP90AB1 and RPLP0 functioning in protein folding 
and processing form a small close network, suggesting that 9S-HOD may regulate this pathway. Among these proteins, hot shock protein 90 (Hsp90) is associated with tumorigenesis. The availability of drugs that can specifically target Hsp90 and inhibit its function, resulting in the depletion of client proteins, has made Hsp90 a novel and exciting target for the development of anti-tumor drugs [15]. Hsp90 has two main isoforms, namely, Hsp90-alpha (Hsp90AA1) and Hsp90-beta (Hsp90AB1) [16]. A study of various tumor cell lines revealed that Hsp90-beta was up-regulated expression in A549, H520, H446 and HL-60 cell lines [17]. In our results, we detected the remarkably 4-fold down-regulated expression of Hsp90AB1 in the 9S-HOD treated group, implicating that 9S-HOD may affect on the protein folding and thus inhibited cell proliferation. Meanwhile, EPB41 with functioning in positive regulation of protein binding was upregulated by $9 \mathrm{~S}-\mathrm{HOD}$ treatment.

On 2-DE, PCNA is usually detected as a single spot, as previously described [18]. The exactly PCNA theoretical parameters is $\mathrm{pI} \sim 4.57$ and mass $\sim 30 \mathrm{kDa}$ on the $2-\mathrm{DE}$ map. The PCNA spot in this study corresponded to a polypeptide of pI 4.31 and mass $29 \mathrm{kDa}$, showing that the PCNA is not post-translational modified [19]. It is also interesting to note that PNCA protein was the core node associated with many other proteins in the network. PCNA is the key cell cycle marker protein, involving in DNA replication, DNA repair, chromatin remodeling and epigenetics $[20,21]$. Interaction with different protein partners is an important regulatory mechanism for the diverse functions of PCNA. Since more than 100 PCNAinteracting proteins and several PCNA modifications have already been reported [22]. Among the proteins involved in protein processing, EPB41 and Hsp90AB1 were interactive with PCNA in this study, which also has been verified previously $[23,24]$. It is reported that PCNA was one of the Hsp90 client proteins in HCT-116 [24], suggesting that the association of PCNA with Hsp90 might be a general phenomenon in cancer cells. The same phenomenon was found in our results that Hsp90AB1 and PCNA protein were down-regulated by 9S-HOD in HL-60.

Another interesting protein is the 60s acidic ribosomal protein p0 (RPLP0), which belongs to the L10P family of ribosomal proteins. Proteomic profiling pointed to an association between RPLP0 up-regulation and cancer in several tumor cells [25], which is involved in mRNA translation. In addition, a recent report showed that RPLP0 was up-regulated in patients with the most common types of cancer, indicating that the expression level of RPLP0 could be useful as a prognostic marker in tumors [26]. In our study, 9S-HOD caused downregulated of RPLP0 protein in HL-60 cells.

Three proteins had been demonstrated to be related with mRNA metabolic process, including KIAA1429,
CBX3 and hnRNPK. RNA process is important for the proliferation of tumor cells and RNAi knock-down of RNA processing proteins in cancer cells induces apoptosis [27]. In agreement with these findings, the protein hnRNPK was significantly down-regulated by 9S-HOD. hnRNPK is a nucleic acid-binding protein that serves as a docking platform integrating transduction pathways to nucleic acid-directed processes [28]. Knock-down of hnRNPK results in strongly reduced migratory activity of cancer cells, strongly suggesting hnRNPK as a promising target molecule for cancer progression [29].

\section{Conclusion}

In conclusion, 9S-HOD exerted cytotoxicity efficacy and induced apoptosis in HL-60 cells, and the cytotoxicity was largely attenuated by the presence of FBS in culture media. A classical proteomic approach is performed to elucidate the mechanism of its anti-leukemia activity by 9S-HOD. Based on 2-DE and MALDI-TOF-MS, 23 differentially expressed proteins were identified. Bioinformatics analysis on the proteomic alterations suggested that 9S-HOD may affect several pathways such as mRNA metabolic process, protein binding, DNA replication and apoptosis. However, further studies would be necessary to clarify the exact targets by 9S-HOD in treating leukemia.

\section{Abbreviations \\ 13-HOD: 13-hydroxy-octadecadienoic acid; 15-LOX: 15-lipoxygenase; 2- DE: Two-dimensional gel electrophoresis; 9-HOD: 9-hydroxy-octadecadienoic acid; 9S-HOD: 9s-hydroxy-octadecadienoic acid; AML: Acute myeloid leukemia; DAPI: Dihydrochloride; FBS: Fetal bovine serum; HODEs: Hydroxyl- octadecadienoic acids; MS: Mass spectrometry; PI: Propidium iodide; PMFs: Peptide mass fingerprints; t10,c12-CLA: t10,c12-Conjugated linoleic acid}

\section{Acknowledgements}

Not applicable.

\section{Funding}

This study was supported by the National Natural Science Foundation of China (No. 81200394).

\section{Availability of data and material}

Data sharing not applicable to this article as no datasets were generated or analyzed during the current study.

\section{Authors' contributions}

ZL performed the majority of experiments; $B C, P W, X L, G C, W W$ provided vital analysis and interpretation of data and were also involved in editing the manuscript; WD designed the study and wrote the manuscript. All authors read and approved the final manuscript.

\section{Competing interest}

The authors declare that they have no competing interests.

\section{Consent for publication}

Not applicable.

Ethics approval and consent to participate

Not applicable.

Received: 17 November 2015 Accepted: 1 November 2016 Published online: 10 November 2016 


\section{References}

1. Lindsley RC, Mar BG, Mazzola E, Grauman PV, Shareef S, Allen SL, et al. Acute myeloid leukemia ontogeny is defined by distinct somatic mutations. Blood. 2015;125:1367-76.

2. Bahar MA, Andoh T, Ogura K, Hayakawa Y, Saiki I, Kuraishi Y. Herbal medicine goshajinkigan prevents paclitaxel-induced mechanical allodynia without impairing antitumor activity of paclitaxel. Evid Based Complement Alternat Med. 2013;2013:849754.

3. Buchi F, Pastorelli R, Ferrari G, Spinelli E, Gozzini A, Sassolini F, et al. Acetylome and phosphoproteome modifications in imatinib resistant chronic myeloid leukaemia cells treated with valproic acid. Leuk Res. 2011 35:921-31.

4. Mosblech A, Feussner I, Heilmann I. Oxylipins: structurally diverse metabolites from fatty acid oxidation. Plant Physiol Biochem. 2009:47:511-7.

5. Simsek S, Doehlert DC. Oxygenated fatty acids isolated from wheat bran slurries. Int J Food Sci Nutr. 2014;65:803-8

6. Ruparel S, Green D, Chen P, Hargreaves KM. The cytochrome P450 inhibitor, ketoconazole, inhibits oxidized linoleic acid metabolite-mediated peripheral inflammatory pain. Mol Pain. 2012;8:73.

7. Chang J, Jiang L, Wang Y, Yao B, Yang S, Zhang B, et al. 12/15 Lipoxygenase regulation of colorectal tumorigenesis is determined by the relative tumor levels of its metabolite 12-HETE and 13-HODE in animal models. Oncotarget. 2015:6:2879-88.

8. Yuan H, Li MY, Ma LT, Hsin MK, Mok TS, Underwood MJ, et al. 15-Lipoxygenases and its metabolites 15(S)-HETE and 13(S)-HODE in the development of non-small cell lung cancer. Thorax. 2010;65:321-6.

9. Pasqualini ME, Heyd VL, Manzo P, Eynard AR. Association between E-cadherin expression by human colon, bladder and breast cancer cells and the 13-HODE: 15-HETE ratio. A possible role of their metastatic potential. Prostaglandins Leukot Essent Fatty Acids. 2003:68:9-16.

10. Hampel JKA, Brownrigg LM, Vignarajah D, Croft KD, Dharmarajan AM, Bentel JM, et al. Differential modulation of cell cycle, apoptosis and PPARY2 gene expression by PPARy agonists ciglitazone and 9-hydroxyoctadecadienoic acid in monocytic cells. Prostaglandins Leukot Essent Fatty Acids. 2006; 74:283-93.

11. Cabral M, Martin-Venegas R, Moreno JJ. Differential cell growth/apoptosis behavior of 13-hydroxyoctadecadienoic acid enantiomers in a colorectal cancer cell line. Am J Physiol Gastrointest Liver Physiol. 2014;307:G664-71.

12. Rosenfeld J, Capdevielle J, Guillemot JC, Ferrara P. In-gel digestion of proteins for internal sequence analysis after one- or two-dimensional gel electrophoresis.Anal Biochem.1992;203:173-9.

13. Vangaveti VN, Shashidhar VM, Rush C, Malabu UH, Rasalam RR, Collier F, et al. Hydroxyoctadecadienoic acids regulate apoptosis in human THP-1 cells in a PPARy-dependent manner. Lipids. 2014;49(12):1181-92.

14. Li Z, Tran VH, Duke RK, Ng MC, Yang D, Duke CC. Synthesis and biological activity of hydroxylated derivatives of linoleic acid and conjugated linoleic acids. Chem Phys Lipids. 2009:158:39-45.

15. Richardson PG, Mitsiades CS, Laubach JP, Lonial S, Chanan-Khan AA, Anderson KC. Inhibition of heat shock protein 90 (HSP90) as a therapeutic strategy for the treatment of myeloma and other cancers. Br J Haematol. 2011;152:367-79.

16. Langer T, Fasold H. Isolation and quantification of the heat shock protein 90 alpha and beta isoforms from rat liver. Protoplasma. 2001:218:54-6.

17. Biaoxue R, Xiling J, Shuanying Y, Wei Z, Xiguang C, Jinsui W, et al. Upregulation of Hsp90-beta and annexin A1 correlates with poor survival and lymphatic metastasis in lung cancer patients. J Exp Clin Cancer Res. 2012;31:70.

18. Jiang N, Kham SK, Koh GS, Suang Lim JY, Ariffin H, Chew FT, et al. Identification of prognostic protein biomarkers in childhood acute lymphoblastic leukemia (ALL). J Proteomics. 2011;74(6):843-57.

19. Naryzhny SN, Lee $\mathrm{H}$. Characterization of proliferating cell nuclear antigen (PCNA) isoforms in normal and cancer cells: there is no cancer-associated form of PCNA. FEBS Lett. 2007;581:4917-20.

20. Miller A, Chen J, Takasuka TE, Jacobi JL, Kaufman PD, Irudayaraj JM, et al. Proliferating cell nuclear antigen (PCNA) is required for cell cycle-regulated silent chromatin on replicated and nonreplicated genes. J Biol Chem. 2010; 285:35142-54.

21. Strzalka W, Ziemienowicz A. Proliferating cell nuclear antigen (PCNA): a key factor in DNA replication and cell cycle regulation. Ann Bot. 2011;107:1127-40.

22. Naryzhny SN. Proliferating cell nuclear antigen: a proteomics view. Cell Mol Life Sci. 2008;65:3789-808.
23. Ewing RM, Chu P, Elisma F, Li H, Taylor P, Climie S, et al. Large-scale mapping of human protein-protein interactions by mass spectrometry. Mol Syst Biol. 2007;3:89.

24. Wang X, Heuvelman DM, Carroll JA, Dufield DR, Masferrer JL. Geldanamycininduced PCNA degradation in isolated Hsp90 complex from cancer cells. Cancer Invest. 2010;28:635-41.

25. Frozza CO, Ribeiro TS, Gambato G, Menti C, Moura S, Pinto PM, et al. Proteomic analysis identifies differentially expressed proteins after red propolis treatment in Hep-2 cells. Food Chem Toxicol. 2014;63:195-204.

26. Artero-Castro A, Castellvi J, Garcia A, Hernandez J, Ramon YCS, Lleonart ME. Expression of the ribosomal proteins Rplp0, Rplp1, and Rplp2 in gynecologic tumors. Hum Pathol. 2011;42:194-203.

27. Naoghare PK, Tak YK, Kim MJ, Han E, Song JM. Knock-down of argonaute 2 (AGO2) induces apoptosis in myeloid leukaemia cells and inhibits siRNA-mediated silencing of transfected oncogenes in HEK-293 cells. Basic Clin Pharmacol Toxicol. 2011;109:274-82.

28. Barboro P, Ferrari N, Balbi C. Emerging roles of heterogeneous nuclear ribonucleoprotein K (hnRNP K) in cancer progression. Cancer Lett. 2014 352:152-9.

29. Marques HM, Simpson D, Ngok SP, Nieves B, Chen R, Siprashvili Z, et al. Long non-coding RNA EWSAT1-mediated gene repression facilitates Ewing sarcoma oncogenesis. J Clin Invest. 2014;124:5275-90.

\section{Submit your next manuscript to BioMed Central and we will help you at every step:}

- We accept pre-submission inquiries

- Our selector tool helps you to find the most relevant journal

- We provide round the clock customer support

- Convenient online submission

- Thorough peer review

- Inclusion in PubMed and all major indexing services

- Maximum visibility for your research

Submit your manuscript at www.biomedcentral.com/submit
Biomed Central 